\title{
CCL21-expressing H1944 Cell Vaccine
}

National Cancer Institute

\section{Source}

National Cancer Institute. CCL21-expressing H1944 Cell Vaccine. NCI Thesaurus. Code C98281.

A cancer cell vaccine comprised of the allogeneic human lung adenocarcinoma cell line H1944 that has been transduced ex vivo with adenoviral vector encoding human cytokine chemokine C-C motif ligand 21 (CCL21), with potential immunomodulating and antineoplastic activities. Upon administration, CCL21-expressing H1944 cell vaccine expresses the chemokine CCL21, which may induce an antitumoral cytotoxic Tlymphocyte immune response in the tumor microenvironment. CCL21 has been shown to attract antigen presenting cells (APCs), like leukocytes and DCs, and natural killer (NK) cells and their T-cell effectors to induce a cytotoxic immune response. H1944 cells contain tumor-associated antigens (TAAs) overexpressed in non-small cell lung cancer (NSCLC). 